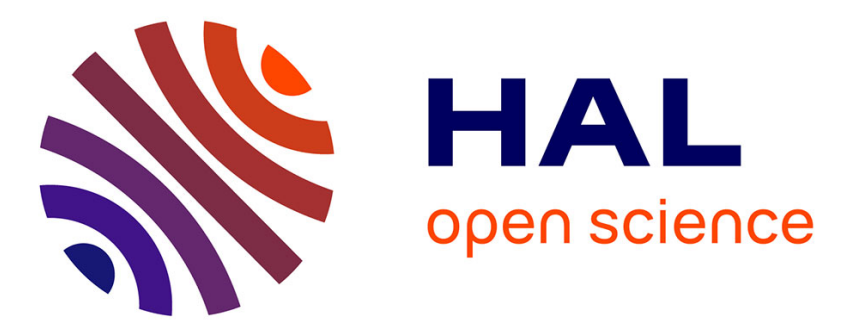

\title{
Interaction of europium and nickel with calcite studied by Rutherford Backscattering Spectrometry and Time-Resolved Laser Fluorescence Spectroscopy
}

A Sabau, Y Pipon, N Toulhoat, C Lomenech, N Jordan, N Moncoffre, A Barkleit, N Marmier, V Brendler, S Surblé, et al.

\section{To cite this version:}

A Sabau, Y Pipon, N Toulhoat, C Lomenech, N Jordan, et al.. Interaction of europium and nickel with calcite studied by Rutherford Backscattering Spectrometry and Time-Resolved Laser Fluorescence Spectroscopy. Nuclear Instruments and Methods in Physics Research Section B: Beam Interactions with Materials and Atoms, 2014, 10.1016/j.nimb.2014.02.041 . hal-01306310

\author{
HAL Id: hal-01306310 \\ https://hal.science/hal-01306310
}

Submitted on 22 Apr 2016

HAL is a multi-disciplinary open access archive for the deposit and dissemination of scientific research documents, whether they are published or not. The documents may come from teaching and research institutions in France or abroad, or from public or private research centers.
L'archive ouverte pluridisciplinaire HAL, est destinée au dépôt et à la diffusion de documents scientifiques de niveau recherche, publiés ou non, émanant des établissements d'enseignement et de recherche français ou étrangers, des laboratoires publics ou privés. 


\title{
Interaction of Europium and Nickel with calcite studied by Rutherford Backscattering Spectrometry and Time-Resolved Laser Fluorescence Spectroscopy
}

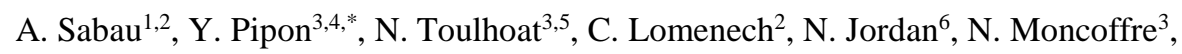 \\ A. Barkleit ${ }^{6}$, N. Marmier ${ }^{2}$, V. Brendler ${ }^{6}$, S. Surbléf,8, E. Giffaut ${ }^{1}$
}

${ }^{1}$ Agence Nationale pour la gestion des Déchets RAdioactifs, 1-7 rue J. Monnet, Parc de la Croix Blanche, 92298 Châtenay-Malabry Cedex, France.

${ }^{2}$ Université de Nice Sophia Antipolis, Ecosystèmes Côtiers Marins et Réponses aux Stress (ECOMERS), 28 avenue Valrose, 06108 Nice Cedex 2, France.

${ }^{3}$ Institut de Physique Nucléaire de Lyon (IPNL), Université Lyon 1, CNRS/IN2P3, 4 rue Enrico Fermi, 69622 Villeurbanne Cedex, France.

${ }^{4}$ Institut Universitaire de Technologie (IUT) Lyon-1, Université Claude Bernard Lyon 1, 69622 Villeurbanne Cedex, France.

${ }^{5}$ CEA/DEN, Saclay, 91191 Gif sur Yvette, France

${ }^{6}$ Helmholtz Zentrum Dresden Rossendorf (HZDR), Institute of Resource Ecology (IRE), Germany.

${ }^{7}$ CEA / IRAMIS / SIS2M / LEEL, F-91191 Gif-sur-Yvette, France.

${ }^{8}$ CNRS / UMR 3299 / SIS2M / LEEL, F-91191 Gif-sur-Yvette, France.

\footnotetext{
* Corresponding author. Present address: IPNL, Bâtiment Paul Dirac, 4, rue Enrico Fermi, F-69622 Villeurbanne cedex, France. Tel.: +334 72431057 (Y. Pipon). E-mail: pipon@ipnl.in2p3.fr
}

\begin{abstract}
This study aims at elucidating the mechanisms regulating the interaction of $\mathrm{Eu}$ and $\mathrm{Ni}$ with calcite $\left(\mathrm{CaCO}_{3}\right)$. Calcite powders or single crystals (some mm sized) were put into contact with Eu or Ni solutions at concentrations ranging from $10^{-3}$ to $10^{-5}$ mol.L $\mathrm{L}^{-1}$ for $\mathrm{Eu}$ and $10^{-3}$ mol. $\mathrm{L}^{-1}$ for $\mathrm{Ni}$. The sorption durations ranged from one week to one month. Rutherford Backscattering Spectrometry (RBS) well adapted to discriminate incorporation processes such as: (i) adsorption or co precipitation at the mineral surfaces or, (ii) incorporation into the mineral structure (through diffusion for instance), has been carried out. Moreover, using the fluorescence properties of Europium, the results have been compared to those obtained by Time-Resolved Laser Fluorescence Spectroscopy (TRLFS) on calcite powders. For the single crystals, complementary SEM observations of the
\end{abstract}


mineral surfaces at low voltage were also performed. Results showed that Ni accumulates at the calcite surface whereas Eu is also incorporated at a greater depth. Eu seems therefore to be incorporated into two different states in calcite: (i) heterogeneous surface accumulation and (ii) incorporation at depth greater than $160 \mathrm{~nm}$ after 1 month of sorption. Ni was found to accumulate at the surface of calcite without incorporation.

\section{Keywords}

Calcite; Europium; Nickel; RBS; TRLFS, Sorption.

\section{Introduction}

Calcium carbonate minerals are present in the French Callovo Oxfordian shales where the radioactive waste should be disposed of. An important number of waste repository concepts enclose cement base components and calcite is the main secondary alteration product formed during the degradation of cement over geological time scales [1]. Europium is a fission product $\left({ }^{154} \mathrm{Eu}\right.$ and ${ }^{155} \mathrm{Eu}$, with $\mathrm{t}_{1 / 2}=8.6$ years and 4.7 years, respectively) also used as analogue of trivalent actinides. Nickel is an activation product $\left({ }^{63} \mathrm{Ni}\right.$ and ${ }^{59} \mathrm{Ni}$, with $\mathrm{t}_{1 / 2}=100.1$ years and $7.6 \times 10^{4}$ years, respectively). Therefore, for safety reasons, the evaluation of the retention capabilities of calcite with respect to these radionuclides has to be fully understood. Interactions between cations and natural or synthetic calcite may include incorporation processes, resulting in the irreversibility of some sorption reactions. Understanding and quantification of poorly to non-reversible trapping mechanisms can be considered as a significant improvement in the description of a geological barrier or a backfill material performance in the safety assessment. Little is known about the mechanism of the transfer process from the surface to the bulk. Trapping of ions can proceed either via progressive incorporation into the lattice of the solid, including continuous dissolution/precipitation processes and diffusion or via irreversible surface precipitation.

Rutherford Backscattering spectroscopy (RBS) is an analysis technique that is widely used to follow the incorporation or migration of different elements in minerals. For example, the incorporation of rare earth elements (REE) and $\mathrm{Pb}$ and $\mathrm{Sr}$ into calcite and into apatite has been studied by Cherniak [2-5]. The comparison of the results of these studies proves that these elements diffuse rather rapidly into calcite in comparison to other minerals. Alonso et al. [6] investigated the diffusion of Eu, U, Sr and Re into clay by means of RBS, and clearly showed different behaviors for Eu and U (strong adsorbing elements) compared with $\mathrm{Sr}$ and Re. Carroll [7] combined a RBS study to SEM and EDS measurements and observed the incorporation of U(VI), Nd and Th(IV) in calcite as solid solutions. 
Europium's luminescent properties enable the use of TRLFS to elucidate interaction mechanisms with calcite. Fernandes et al. [8] successfully demonstrated the formation of solid solution between $\mathrm{Eu}^{3+}$ with calcite, by substitution of $\mathrm{Ca}^{2+}$ on the lattice site [9]. Calcite presented both surface sorption and incorporation capacities for Eu(III) [9]. The incorporation had already been evidenced by Piriou et al. [10]. Schmidt et al. [11] studied Eu sorption onto aragonite (metastable $\mathrm{CaCO}_{3}$ ) and found only structural incorporation of $\mathrm{Eu}^{3+}$, without any surface sorption. The reactivity of $\mathrm{CaCO}_{3}$ was thus shown to be dependent on its polymorphism. Substitution of divalent $\mathrm{Ca}^{2+}$ by trivalent $\mathrm{Eu}^{3+}$ was found to be accompanied by a charge compensation which proceeds via a coupled substitution mechanism, originating from the simultaneous substitution of two $\mathrm{Ca}^{2+}$ by one $\mathrm{Eu}(\mathrm{III})$ and one $\mathrm{Na}^{+}$ ion $[8,9]$.

Our work aims at studying the different mechanisms leading to a potential incorporation of europium and nickel in calcite. We have decided to work on the $\mathrm{Eu}-\mathrm{CO}_{2}-\mathrm{NaCl}-\mathrm{CaCO}_{3}$ and $\mathrm{Ni}-\mathrm{CO}_{2}-\mathrm{NaCl}-\mathrm{CaCO}_{3}$ system at $\mathrm{pH} \sim 8.3$, buffered by calcite under air and corresponding to the typical $\mathrm{pH}$ range of natural interstitial groundwaters. Our study relies on the RBS technique to comprehensively characterize the $\mathrm{Eu}-\mathrm{CO}_{2}-\mathrm{NaCl}-\mathrm{CaCO}_{3}$ and the Ni-CO $\mathrm{NaCl}-\mathrm{CaCO}_{3}$, and associates TRLFS analyses for $\mathrm{Eu}$. The investigated samples were prepared under atmospheric conditions, on different calcite samples (powders and millimetric crystals), for different initial concentrations of europium and nickel, these parameters being assumed to be amongst the most important controlling the sorption mechanisms.

\section{Materials and methods}

\subsection{Materials}

At first, an appropriate material for sorption experiments was selected based on characterization studies. From a variety of sources, the attention was focused on two calcite powders from SOLVAY (SOCAL U1-R) and from OMYA (Hydrocarb 90). The particle size was estimated by Scanning Electron Microscopy (SEM) to be, respectively, $\sim 0.2 \mu \mathrm{m}$ and $\sim 50 \mu \mathrm{m}$. The specific surface areas were determined to be, respectively, $18.4 \mathrm{~m}^{2} \mathrm{~g}^{-1}$ and $0.66 \mathrm{~m}^{2} \mathrm{~g}^{-1}$ by applying the Brunauer-Emmet-Teller (BET) equation with nitrogen adsorption isotherms at 77 K (Multi-point Beckman Coulter Surface Analyzer SA 3100). Purity of the calcite samples and absence of polymorphic $\mathrm{CaCO}_{3}$ compounds (i.e. vaterite and aragonite) were confirmed by XRD (X-ray Diffraction), DRIFT (Diffuse Reflectance Infra-Red Fourier Transform Spectroscopy) and TEM (Transmission Electron Microscopy). Elemental analysis performed by ICP-MS (Inductively Coupled Plasma-Mass Spectrometry, ELAN 9000 Perkin Elmer) after digestion showed the absence of Ni in the SOLVAY sample $\left(<0.01 \mu \mathrm{g} \mathrm{g}^{-1}\right)$ and 
the presence of a very low concentration of $\mathrm{Eu}\left(5.83 .10^{-2} \mu \mathrm{g} \mathrm{g}^{-1}\right)$, whereas in the OMYA sample a small amount of $\mathrm{Ni}$ was detected $\left(13.11 \mu \mathrm{g} \mathrm{g}^{-1}\right)$, whereas Eu was not detected $\left(<0.01 \mu \mathrm{g} \mathrm{g}^{-1}\right)$. Single crystals provided by Alfa Aesar were also investigated, with a surface size around $1 \times 1 \mathrm{~mm}^{2}$ and a thickness of 2 to $3 \mathrm{~mm}$. Small amounts of $\mathrm{Eu}\left(<0.07 \mu \mathrm{g} \mathrm{g}^{-1}\right)$ and for $\mathrm{Ni}\left(0.41 \mu \mathrm{g} \mathrm{g}^{-1}\right)$ were determined by ICP-MS after digestion of $50 \mathrm{mg}$ of single crystals.

\subsection{Sample preparation}

The europium $\left(5 \times 10^{-3} \mathrm{M}\right)$ and nickel $\left(2 \times 10^{-3} \mathrm{M}\right)$ stock solutions were prepared by dissolving $\mathrm{EuCl}_{3} \cdot 6 \mathrm{H}_{2} \mathrm{O}$ (Sigma-Aldrich, trace elements basis, 99.99\%) and $\mathrm{NiCl}_{2} .6 \mathrm{H}_{2} \mathrm{O}$ (Sigma-Aldrich, 99\%) in UHQ water. All experiments were carried out using diluted fractions of these solutions. All sorption experiments were done under atmospheric conditions $\left(\mathrm{pCO}_{2}=10^{-3.5} \mathrm{~atm}\right)$ and carried out in duplicate.

For powder samples, $500 \mathrm{mg}$ of calcite was suspended in $100 \mathrm{~mL}$ of $0.1 \mathrm{~mol} \mathrm{~L}{ }^{-1} \mathrm{NaCl}$ solution in Teflon vials, to get a mass-volume ratio of $5 \mathrm{~g} \mathrm{~L}^{-1}$. A first step resulting in the pre-equilibration of calcite was performed, i.e. the calcite suspension was stirred until an equilibrium $\mathrm{pH}$ of $\sim 8.3$ was reached. Required amounts of europium were then added to reach a europium concentration of $10^{-3}$ and $10^{-4} \mathrm{~mol} \mathrm{~L}^{-1}$ and a nickel concentration of $10^{-3} \mathrm{~mol}$ $\mathrm{L}^{-1}$ at ambient pressure and temperature and the samples were subsequently stirred during 1 month. After sorption, the suspension was directly measured by TRLFS and for RBS experiments, samples were centrifuged at $5000 \mathrm{rpm}$ for 30 minutes, the solid was dried in air for 4 days and then compacted to pellets about $1 \mathrm{~cm}$ in diameter.

For millimetric single crystals, 10 to 12 crystals (resulting in a solid/liquid ratio of $0.3 \mathrm{~g} \mathrm{~L}^{-1}$ ) were directly immersed in $100 \mathrm{~mL}$ of a Eu or Ni-enriched solution $\left(10^{-5}\right.$ and $10^{-4} \mathrm{~mol} \mathrm{~L}-1$ for $\mathrm{Eu}, 10^{-4}$ and $10^{-3} \mathrm{~mol} \mathrm{~L}^{-1}$ for $\left.\mathrm{Ni}\right)$, since the pre-equilibration could not be reached easily; the $\mathrm{pH}$ was adjusted using a dilute $\mathrm{NaOH}$ solution to reach a value of $\sim 8.3$. Two contact times ( 1 week and 1 month) were selected, during which the solution was periodically stirred by hand. For the RBS measurements, powders were pressed to pellets and were, as well as the single crystals, coated with a layer of carbon (about $10 \mathrm{~nm}$ ) prior to the measurement in order to prevent charging of the surface.

\subsection{TRLFS}

The TRLFS measurements were carried out with a pulsed flash lamp pumped Nd:YAG-OPO laser system (Powerlite Precision II 9020 laser equipped with a Green PANTHER EX OPO from Continuum, Santa Clara, 
CA, USA) at an excitation wavelength of $394 \mathrm{~nm}$ and a constant time gate width of $1 \mathrm{~ms}\left(10^{-5}\right.$ and $10^{-4} \mathrm{~mol} \mathrm{~L}^{-1}$ $\left.\mathrm{Eu}^{3+}\right)$ or $0.1 \mathrm{~ms}\left(10^{-3} \mathrm{~mol} \mathrm{~L}^{-1} \mathrm{Eu}^{3+}\right)$. Details on the laser system are given elsewhere [12]. Static and timeresolved luminescence spectra of $\mathrm{Eu}^{3+}$ were recorded in the range of $570-650 \mathrm{~nm}\left(1200\right.$ lines $\mathrm{mm}^{-1} \mathrm{grating}, 0.2$ $\mathrm{nm}$ resolution) and $550-740 \mathrm{~nm}\left(300\right.$ lines $\mathrm{mm}^{-1}$ grating, $0.7 \mathrm{~nm}$ resolution), respectively. For time-resolved measurements, 61 spectra with delay steps of $20,50,250$ or $500 \mu$ s, depending on the luminescence lifetime, were recorded per sample. The luminescence spectra were analyzed using OriginPro 7.5G (OriginLab, Northhampton, MA, USA) to obtain peak positions and lifetimes. The lifetimes were calculated by fitting the integrated luminescence signal to a sum of exponential decay functions:

$$
E(t)=\sum_{i} E_{i} \cdot \exp \left(-t / \tau_{i}\right)
$$

where $\mathrm{E}$ is the total luminescence intensity at the time $\mathrm{t}, \mathrm{E}_{\mathrm{i}}$ the initial luminescence intensity of the species $\mathrm{i}$ at $\mathrm{t}$ $=0$, and $\tau_{\mathrm{i}}$ the corresponding lifetime.

The number of water molecules in the first coordination shell of $\mathrm{Eu}^{3+}$ was determined from the luminescence lifetimes $\tau$ (in ms) using the linear relationship developed by Horrocks and Sudnick [13] and the resultant empirical formula from Kimura and Choppin [14]. This equation is only valid for lifetimes higher than $110 \mu \mathrm{s}$.

$$
\mathrm{n}\left(\mathrm{H}_{2} \mathrm{O}\right) \pm 0.5=1.07 \cdot \tau^{-1}-0.62
$$

\subsection{RBS (Rutherford Backscattering Spectrometry) analysis}

RBS analysis was performed at IPNL on a 4 MV Van de Graaff accelerator. Beam was normal to the sample surfaces and ${ }^{4} \mathrm{He}$ detection was performed at $172^{\circ}$ using a surface barrier silicon detector. Two different energies have been used for the incident beam: $4 \mathrm{MeV}$ and 1.5 MeV. The $4 \mathrm{MeV}$ beam allowed probing Eu and $\mathrm{Ni}$ in order to measure the incorporation of $\mathrm{Eu}$ and $\mathrm{Ni}$ in function of depth and the $1.5 \mathrm{MeV}$ experiments were performed in order to increase the surface resolution and to accurately probe the first hundreds nanometers near the surface. The circular incident beam was around $1 \mathrm{~mm}$ in diameter and the current density was kept low with a maximum value of $2 \mu \mathrm{A} \mathrm{cm} \mathrm{cm}^{-2}$ in order to avoid element (Eu or Ni) migration or calcite degradation during RBS analysis.

The SIMNRA 6.06 simulation program [15] was used to simulate the experimental spectra and to determine concentration profiles of $\mathrm{Eu}$ and $\mathrm{Ni}$. Constant layers were used to make the simulation and the thickness value was set to the value of the technique resolution which was determined for each experimental condition with RESOLNRA [16]. 


\section{Results and discussion}

\subsection{Results on powders}

Concerning the analyses by TRLFS, the lifetimes obtained on the SOLVAY powders for three Eu concentrations $\left(10^{-3}, 10^{-4}\right.$ and $\left.10^{-5} \mathrm{~mol} \mathrm{~L}^{-1}\right)$ and two contact times (1 week and 1 month) are presented in Table 1 . Three main observations can be done:

- all measurements reveal two different lifetimes in each sample, indicating two different local environments for Eu in calcite,

- for each concentration, the number of $\mathrm{H}_{2} \mathrm{O}$ molecules remains almost unchanged between 1 week and 1 month, which means that no significant structural changes with time could be observed and,

- an obvious evolution as a function of the initial concentration of Eu(III), since the lifetimes get higher when the concentration decreases.

The first short lifetimes $(195-211 \mu \mathrm{s})$ are close to those found for isolated Eu solid carbonates listed in the literature [17], especially $\mathrm{NaEu}\left(\mathrm{CO}_{3}\right)_{2}: 5 \mathrm{H}_{2} \mathrm{O}$ or $\mathrm{Eu}_{2}\left(\mathrm{CO}_{3}\right)_{3}: \mathrm{nH}_{2} \mathrm{O}$. These short lifetimes could then be attributed to the formation of europium carbonate species at the calcite surface. The lifetimes with an intermediate value (434- $1241 \mu \mathrm{s})$ may be attributed to hydrated species or surface complexes $[8,10,11]$, having had a partial loss of their hydration sphere, 1 or 2 water molecules surrounding europium. Such an environment has been identified in three studies of the literature: while Fernandes et al. [8] associated a measured lifetime of 800-1080 $\mu$ s to the possibility of formation of a europium surface complex on calcite, Piriou et al. [10] also reported intermediate lifetimes of 450 and $850 \mu$ s, corresponding to two types of environment where Eu is surrounded by water or hydroxyl ions, one observed for the highest Eu concentration and being more hydrated than the other one, and Yeghicheyan [18] reported lifetimes of 420 and $560 \mu$ s corresponding to hydrated/hydroxylated environments. Piriou et al. [10] postulated incorporation into a hydrated and/or hydroxylated surface layer of calcite. The higher lifetimes measured in our study $(>1765 \mu$ s) would correspond to a total loss of the hydration sphere, and we may suppose that even already after 1 week, incorporation of Eu(III) in the calcite lattice already took place, despite the measured lifetime is lower than those previously reported in the literature $[8,10,11]$.

Concerning the RBS analyses, calcite powders enriched during 1 month with Eu $\left(10^{-3} \mathrm{M}\right.$ and $\left.10^{-4} \mathrm{M}\right)$ and $\mathrm{Ni}$ $\left(10^{-3} \mathrm{M}\right)$ and pressed to pellets afterwards have been analyzed with a $4 \mathrm{MeV}{ }^{4} \mathrm{He}$ incident beam. At this energy, the depth resolution is about $35 \mathrm{~nm}$ near the surface. It must be noted that two different analyses at different 
points have been made on each pellet and that a good reproducibility was obtained. Figure 1 displays the backscattered ${ }^{4} \mathrm{He}$ spectrum in function of channel obtained on the pellets enriched respectively with $10^{-3} \mathrm{M} \mathrm{Eu}$ (1a) and $10^{-3} \mathrm{M} \mathrm{Ni}(1 \mathrm{~b})$. Two main observations can be made:

- $\quad$ the spectra obtained on the OMYA (50 $\mu \mathrm{m}$ grain size) pellets display a surface peak (of Eu or Ni) that is not present for the SOLVAY $(0.2 \mu \mathrm{m}$ grain size $)$ pellets.

- $\quad$ on the left side of this surface peak (toward the lower channel numbers), the Eu (or Ni) signals, OMYA and SOLVAY pellets, remain equal and constant.

Figure 2 shows the evolution of the $\mathrm{Eu}\left(10^{-3} \mathrm{M}\right.$ and $\left.10^{-4} \mathrm{M}\right)$ and $\mathrm{Ni}\left(10^{-3} \mathrm{M}\right)$ concentration profiles for the OMYA pellets. Each profile displays a surface enrichment which is coherent with a Eu and Ni accumulation or a surface complex as it was evidenced by TRLFS. For the pellets in contact with $10^{-3} \mathrm{M}$ Eu solution, the concentration decreases first strongly until $200 \mathrm{~nm}$ and then slowly until $600 \mathrm{~nm}$ where it remains constant at around 0.4 at. \%. For the pellets in contact with $10^{-4} \mathrm{M}$ Eu solution, the concentration decreases until $200 \mathrm{~nm}$ and then remains constant at around 0.05 at. \%. Ni concentration remains constant beyond $100 \mathrm{~nm}$ at around 0.1 at. $\%$. This constant signal was awaited due to the compaction of the grains powders and to the millimeter beam size which averages the signals from all the probed grains. However, the first points should be spared by this artifact, especially for the OMYA pellets unless the size of the powder grains is lower than expected. This assumption was confirmed by performing optic microscopy on OMYA powders enriched with Eu. The images (not shown here) clearly put into evidences agglomerations of small grains (often with a size lower than $5 \mu \mathrm{m}$ ). Therefore, the small grain size of both powders explains that no peak can be measured on SOLVAY pellets and that a constant signal is measured after some hundreds nanometers on OMYA pellets.

\subsection{RBS results on single crystals}

Single crystals were used and put into contact with Eu solution $\left(10^{-4} \mathrm{M}\right)$ during 1 week and 1 month and with $\mathrm{Ni}$ $\left(10^{-3} \mathrm{M}\right)$ during 1 week and 3 weeks. The crystals were then analyzed separately and the incident beam was set to $1.5 \mathrm{MeV}$ in order to improve the depth resolution and the backscattering yield. At this energy, the depth resolution is better than in the previous analyses performed on the pellets with a value of around $25 \mathrm{~nm}$ at the samples surface. Figure 4 shows the depth concentration profiles of $\mathrm{Eu}\left(10^{-4} \mathrm{M}\right.$ with a contact time of 1 week and 1 month) and $\mathrm{Ni}\left(10^{-3} \mathrm{M}\right.$ with a contact time of 1 week and 3 weeks). Three mains observations can be made: 
- The signals of Eu or Ni drop to zero before reaching a depth of $200 \mathrm{~nm}$ which confirms that for powders samples, we analyzed an average of signals coming from several small grains.

- The surface accumulation is present for all the profiles. If we compare the Eu and Ni profiles of pellets and single crystals enriched with $10^{-4} \mathrm{M}$ (for $\mathrm{Eu}$ ) and $10^{-3} \mathrm{M}$ (for $\mathrm{Ni}$ ) during 1 month (or almost for $\mathrm{Ni}$ ), we can see that the concentration values are close.

- The behavior of $\mathrm{Ni}$ and Eu are very different as it will be explained below.

The Ni concentration decreases sharply in the first $40 \mathrm{~nm}$ and drops to zero at $100 \mathrm{~nm}$ for the both contact times (1 week and 3 weeks) samples which would indicate a surface accumulation and almost no incorporation into the single crystals.

The Eu concentration decreases sharply in the first $40 \mathrm{~nm}$ and drops to zero only at a depth around $175 \mathrm{~nm}$ for the 1 week contact time sample. The profile corresponding to the 1 month contact time sample displays also a surface accumulation of Eu with a sharp decrease in the first $20 \mathrm{~nm}$ but afterwards, the concentration decreases smoothly with the depth. This seems to indicate a surface accumulation and an incorporation of Eu into calcite crystal.

Other single crystals enriched with Eu have been analyzed to check the reproducibility and the concentration values corresponding to the surface enrichment were not at the same level for all crystals whereas the values of the incorporated Eu amounts were close. For example, after 1 month of sorption, the concentration value at the very surface was at 1.2 at. $\%$ instead of 0.3 at. $\%$ as it is shown in Figure 4. SEM experiments were performed at the Centre Technologique des Microstructures of University Lyon 1 and some images are presented in Figure 5. The first image (5a) corresponds to the surface of a virgin calcite (no sorption experiment performed on it) and we can see that the surface is plane and smooth. On the second image (5b), the surface of a calcite which has been put in contact with an Europium solution of $10^{-4} \mathrm{M}$ is shown. Compared to the surface of the virgin sample, the surface has a corroded aspect which means that the surface has been modified by the Europium solution and could have incorporated Eu. The third image (5c) shows another single crystal put in contact with an Europium solution of $10^{-4} \mathrm{~mol} \mathrm{~L}{ }^{-1}$. It can be seen that the surface is partially covered by a "tongue shaped" precipitate topped with some small white cubes and the underlying calcite surface has also a corroded aspect. Some EDX analyses (not shown here) reveal that the precipitate contains significant amounts of Europium and that the white cubes are salt (presence of $\mathrm{Na}$ and $\mathrm{Cl}$ ). These images reveal that the precipitate is heterogeneously distributed which explains that the values of the Eu concentration measured at the surface are not homogeneous. 


\section{Conclusions}

RBS analyses have been performed on calcite powders of two grain sizes pressed to pellets and single crystals that have been put in contact with Eu and Ni solutions. The pellets corresponding to the SOLVAY powder have $0.2 \mu \mathrm{m}$ sized grains that are too small to be used to detect an incorporation process by RBS performed with a millimeter beam. However, RBS analyses of the OMYA pellets reveal that both $\mathrm{Ni}$ and Eu accumulate at the surface of the samples. TRLFS results on SOLVAY powders reveal the possible existence of different Eu species and evidence different mechanisms such as surface precipitation and incorporation. RBS performed on single crystals reveal distinct sorption of behavior of $\mathrm{Eu}$ and $\mathrm{Ni}$ : $\mathrm{Ni}$ accumulates at the calcite surface without being incorporated whereas Eu accumulates at the surface and is also incorporated into the calcite and the amount of incorporated Eu increases with time. It is quite interesting to note that two different spectroscopic techniques such as TRLFS, focusing on bulk samples, and a RBS, having a nanometric resolution, lead to converging results. In order to confirm our results and to get more insight into the sorption mechanisms of Eu into calcite, experiments using a microbeam are scheduled at the CEA Saclay accelerator in order to enhance the spatial beam resolution.

\section{Acknowledgements}

The authors would like to thank ANDRA (Agence Nationale pour la gestion des Déchets RAdioactifs) for funding the Ph.D. of Andrea Sabau. We also like to acknowledge the accelerator staff of IPNL for their help during the RBS experiments, Ursula Schaefer and Aline Ritter for ICP-MS measurements, Carola Eckardt for BET determination, Karsten Heim for IR experiments, Andrea Scholz for XRD measurements. Authors are grateful to Stephan Weiss for his scientific support and for the helpful discussions.

\section{References}

[1] M.M. Fernandes, T. Stumpf, T. Rabung, D. Bosbach, T. Fanghanel, Geochim. Cosmochim. Acta 72 (2008) $464-474$.

[2] D.J. Cherniak, Geochim. Cosmochim. Acta 61 (1997) 4173-4179.

[3] D.J. Cherniak, Earth Planet. Sci. Lett. 160 (1998) 273-287.

[4] D.J. Cherniak, F.J. Ryerson, Geochim. Cosmochim. Acta 57 (1993) 4653-4662.

[5] D.J. Cherniak, Geochim. Cosmochim. Acta 64 (2000) 3871-3885. 
[6] U. Alonso, T. Missana, M. Garcia-Gutierrez, A. Patelli, M. Siitari-Kauppi, V. Rigato, Appl. Clay Sci., 43 (2009) 477-484.

[7] S.A. Carroll, J. Bruno, J.-C. Petit, J.-C. Dran, Radiochim. Acta, 58/59 (1992) 245-252.

[8] M.M. Fernandes, M. Schmidt, T. Stumpf, C. Walther, D. Bosbach, R. Klenze, T. Fanghanel, J. Colloid Interface Sci. 321 (2008) 323-331.

[9] M. Schmidt, T. Stumpf, M.M. Fernandes, C. Walther, T. Tanghanel, Angewandte Chemie-International Edition 47 (2008) 5846-5850.

[10] B. Piriou, M. Fedoroff, J. Jeanjean, L. Bercis, J. Colloid Interface Sci. 194 (1997) 440-447.

[11] M. Schmidt, T. Stumpf, C. Walther, H. Geckeis, T. Fanghanel, Dalton Transactions 33 (2009) 6645-6650.

[12] H. Moll, A. Johnsson, M. Schafer, K. Pedersen, H. Budzikiewicz, G. Bernhard, Biometals 21 (2008) 219228.

[13] W.D. Horrocks, D.R. Sudnick, J. Am. Chem. Soc. 101 (1979) 334-340.

[14] T. Kimura, G.R. Choppin, J. Alloys Comp. 213 (1994) 313-317.

[15] M. Mayer, SIMNRA user’s guide, Max-Planck-Institute für Plasmaphysik, Garching, 1997.

[16] M. Mayer, Nucl. Instrum. Methods Phys. Res., Sect. B 266 (2008) 1852-1857.

[17] W. Runde, C. Van Pelt, P.G. Allen, J. Alloys Comp. 303-304 (2000) 182-190.

[18] D. Yeghicheyan, PhD Thesis: "Etude expérimentale du partage des terres rares entre carbonates de calcium et solutions aqueuses : Influence de la cinétique de cristallisation et de la spéciation des terres rares en solution", Université Paul Sabatier, Toulouse, France (1996). 


\section{Figures}

Figure 1: ${ }^{4} \mathrm{He}$ spectra measured by RBS at $4 \mathrm{MeV}$ on pellets of calcite powders $(0.2 \mu \mathrm{m}$ and $50 \mu \mathrm{m}$ grain size $)$ enriched with $10^{-3}$ mol L ${ }^{-1} \mathrm{Eu}$ (a) and $\mathrm{Ni}(\mathrm{b})$ during 1 month.

Figure 2: Depth concentration profiles of Eu (initial sorption with $10^{-3} \mathrm{M}$ and $10^{-4} \mathrm{M}$ solutions during 1 month) and $\mathrm{Ni}$ (initial sorption with $10^{-3} \mathrm{M}$ solution during 1 month) in calcite powders (50 $\mu \mathrm{m}$ grain size). Lines are only plotted to guide the eyes.

Figure 3: Depth concentration profiles of Eu (initial sorption with $10^{-4} \mathrm{M}$ solution during 1 week and 1 month) and $\mathrm{Ni}$ (initial sorption with $10^{-3} \mathrm{M}$ solution during 1 week and 3 weeks) in calcite single crystals. Lines are only plotted to guide the eyes.

Figure 4: SEM images on a virgin calcite single crystal (a) and on two different single crystals enriched with Eu $10^{-4} \mathrm{M}$ during 1 month (b) and (c). 


\section{Table}

Table 1: Fluorescence lifetimes of $\mathrm{Eu}(\mathrm{III})$ sorbed on calcite powders $(0.2 \mu \mathrm{m}$ grain size $)$ as a function of time and initial concentration. $t_{1}$ and $t_{2}$ correspond to the two measured lifetimes in each sample. The number of water molecules surrounding Eu calculated using Horrock’s equation is indicated in brackets. 
Figure 1 (2 columns if possible)

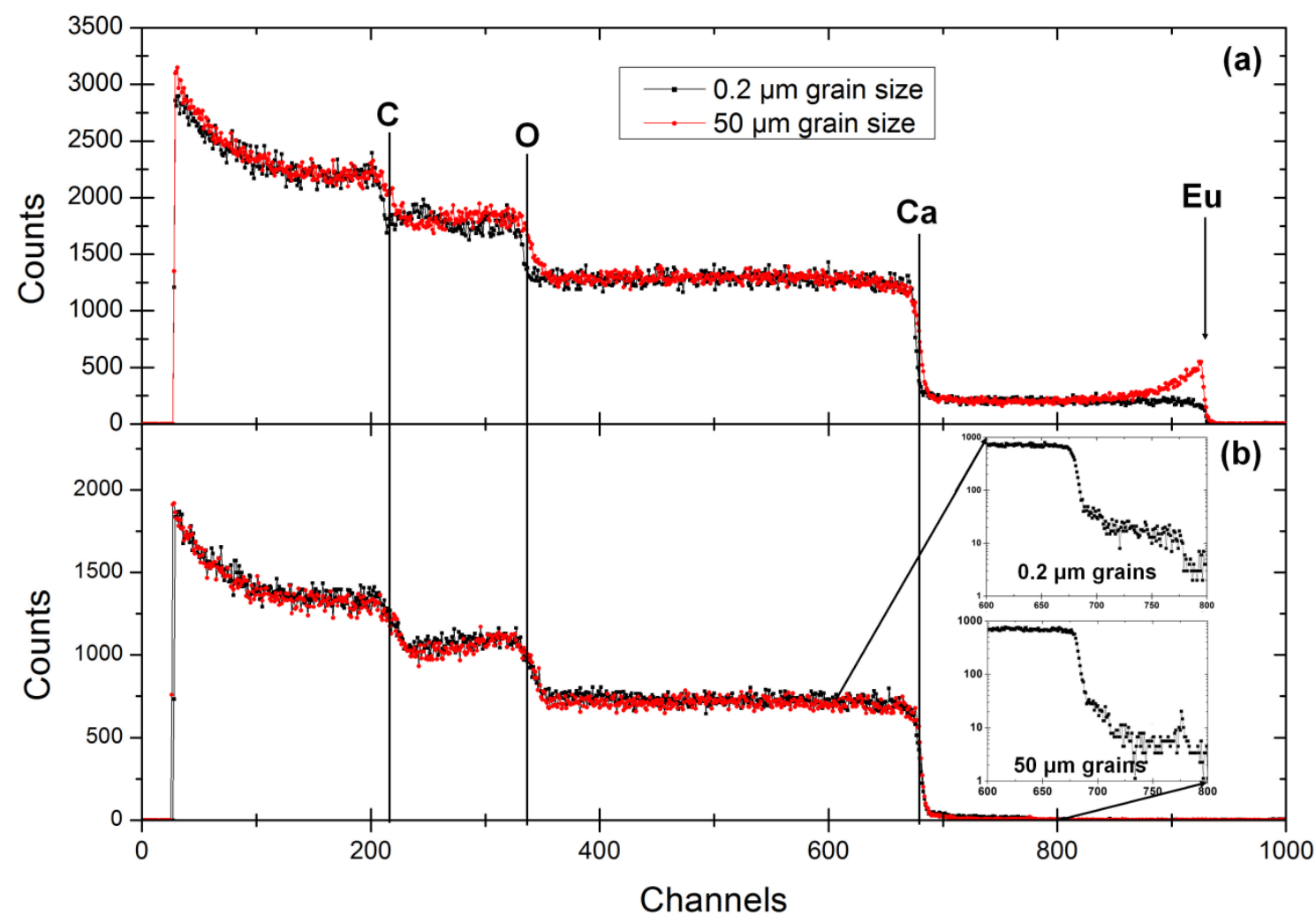


Figure 2 (1 column)

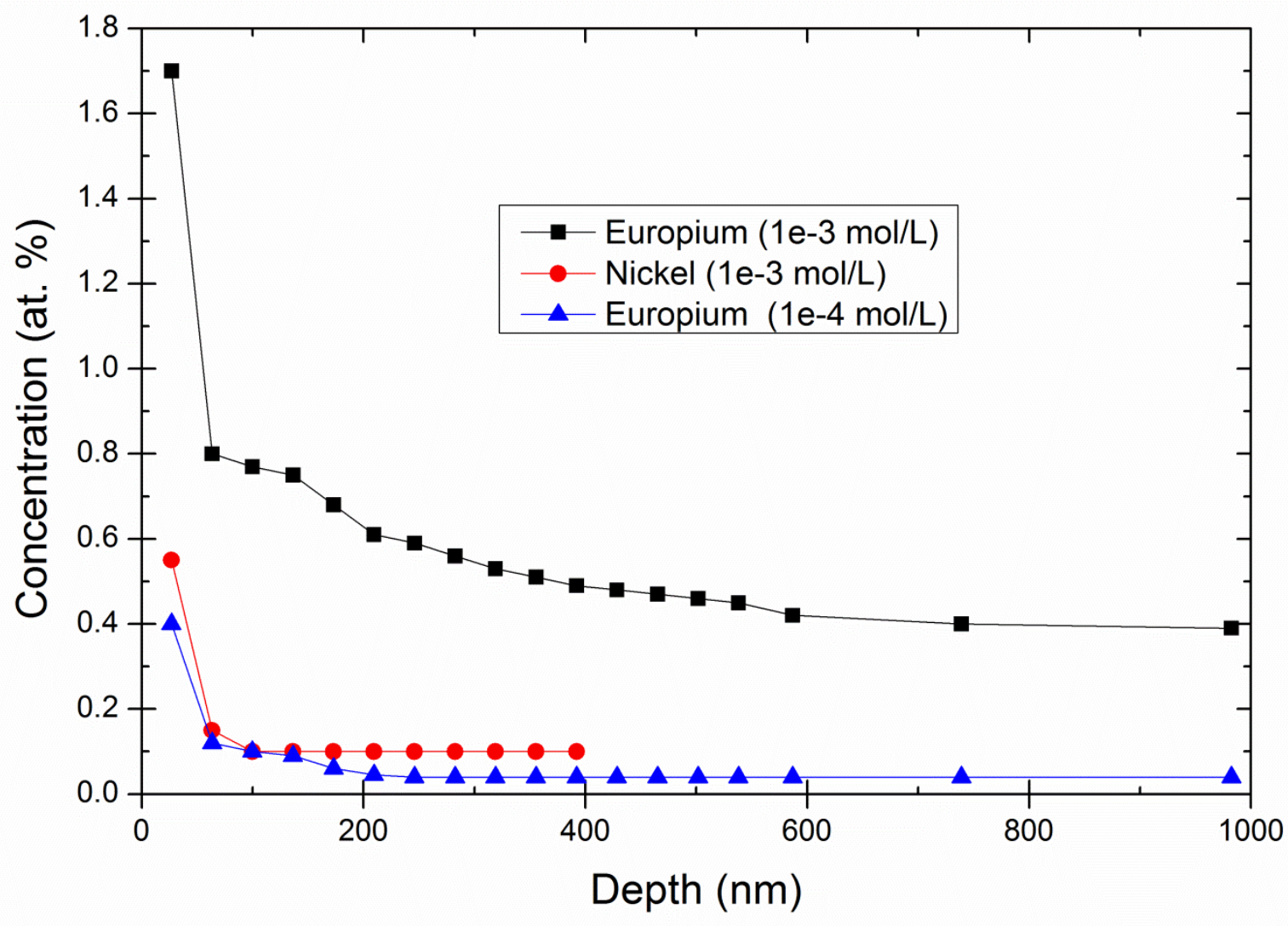


Figure 3 (1 column)

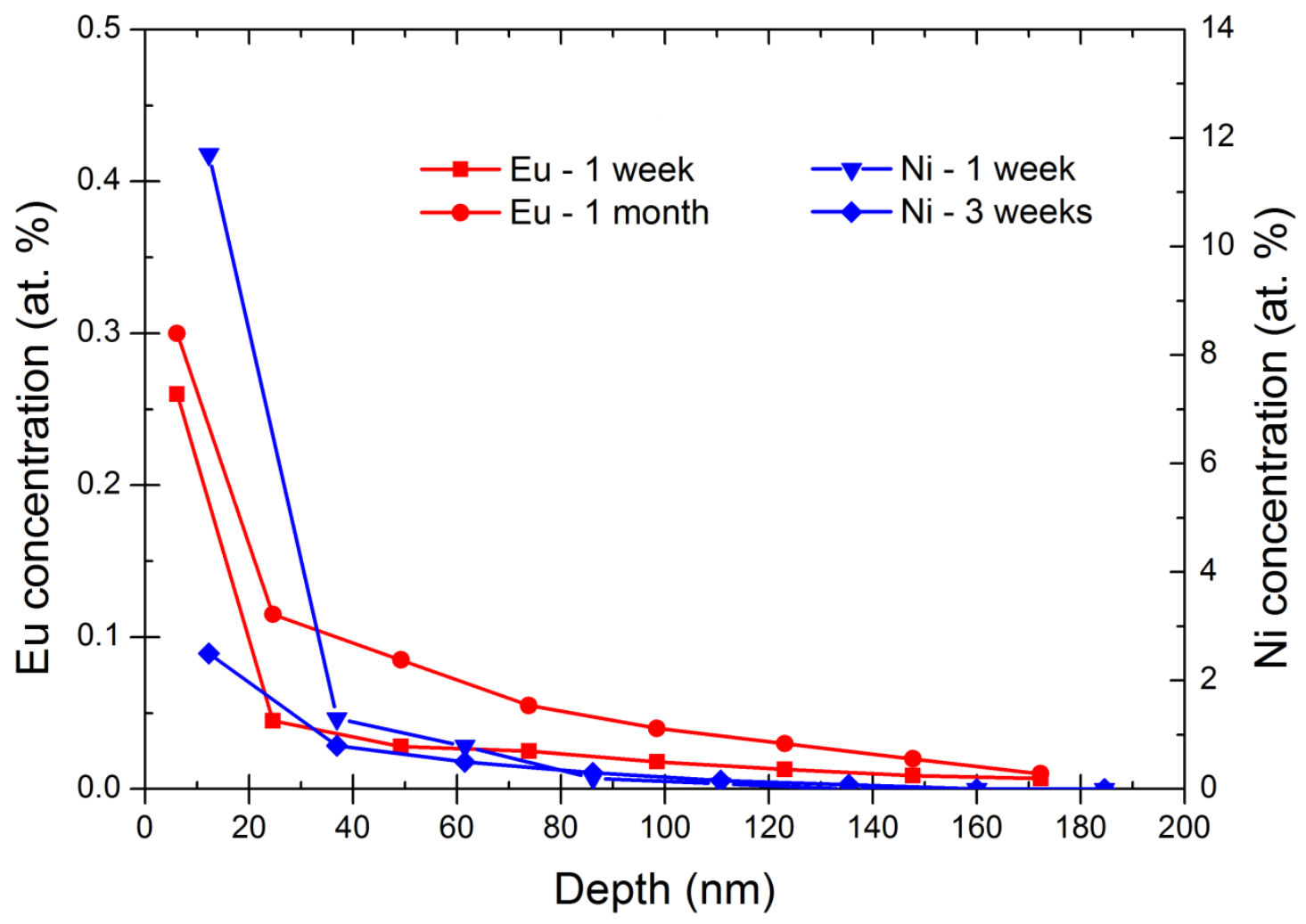


Figure 4 (1 column)
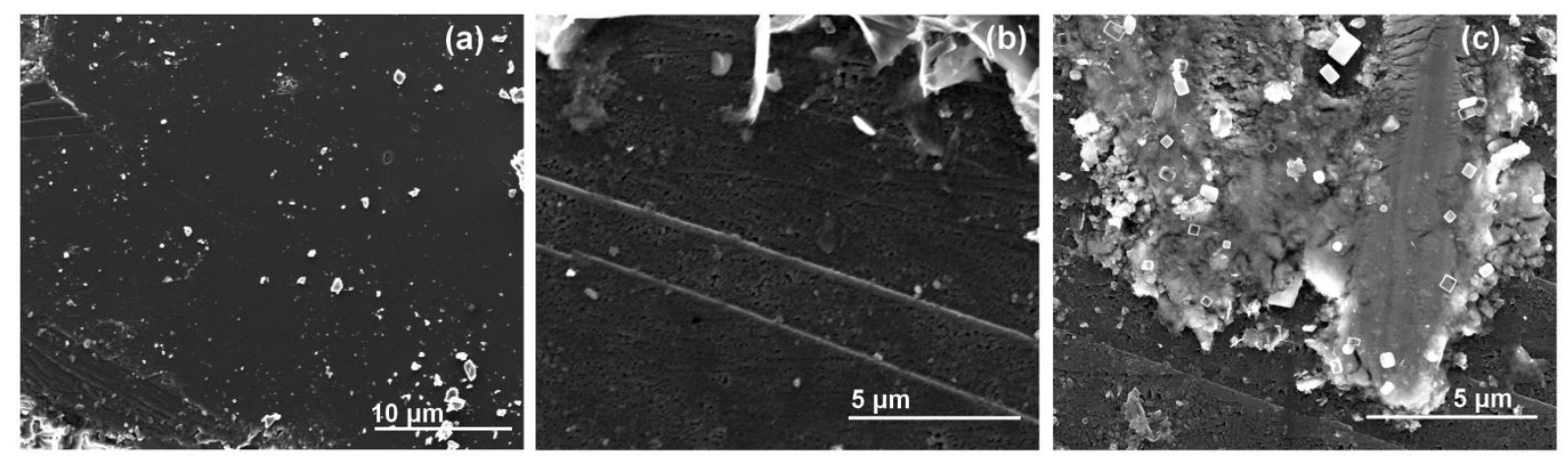
Table 1 (1 column)

\begin{tabular}{|c|c|c|c|c|}
\hline \multirow{2}{*}[\mathrm{Eu}^{3+}]{$_{0}\left(\mathrm{~mol} \mathrm{~L}^{-1}\right)$} & \multicolumn{2}{|c|}{1 week } & $\mathrm{t}_{1}(\mu \mathrm{s})$ & $\mathrm{t}_{2}(\mu \mathrm{s})$ \\
\cline { 2 - 5 } & $\mathrm{t}_{1}(\mu \mathrm{s})$ & $\mathrm{t}_{2}(\mu \mathrm{s})$ & $211 \pm 5$ & $491 \pm 3$ \\
\hline $10^{-3}$ & $195 \pm 4$ & $434 \pm 2$ & $\left(4.5 \pm 0.5 \mathrm{H}_{2} \mathrm{O}\right)$ & $\left(1.6 \pm 0.5 \mathrm{H}_{2} \mathrm{O}\right)$ \\
& $\left(4.9 \pm 0.5 \mathrm{H}_{2} \mathrm{O}\right)$ & $\left(1.8 \pm 0.5 \mathrm{H}_{2} \mathrm{O}\right)$ & $575 \pm 23$ & $1241 \pm 32$ \\
\hline $10^{-4}$ & $591 \pm 25$ & $1189 \pm 32$ & $\left(1.2 \pm 0.5 \mathrm{H}_{2} \mathrm{O}\right)$ & $\left(0.2 \pm 0.5 \mathrm{H}_{2} \mathrm{O}\right)$ \\
\hline & $\left(1.2 \pm 0.5 \mathrm{H}_{2} \mathrm{O}\right)$ & $\left(0.3 \pm 0.5 \mathrm{H}_{2} \mathrm{O}\right)$ & $827 \pm 21$ & $1995 \pm 44$ \\
& $709 \pm 21$ & $1765 \pm 28$ & $\left(0.7 \pm 0.5 \mathrm{H}_{2} \mathrm{O}\right)$ & $\left(0.0 \pm 0.5 \mathrm{H}_{2} \mathrm{O}\right)$ \\
\hline
\end{tabular}

